\title{
The perceptions of physical therapists about facilitators and challenges in the use of different tools for resistance training in COPD patients: a mixed-method study
}

Percepção de fisioterapeutas sobre facilitadores e barreiras no uso de diferentes ferramentas para treinamento resistido em pacientes com DPOC: estudo de método mistos

Percepción de fisioterapeutas sobre facilitadores y barreras en el uso de diferentes herramientas de entrenamiento de resistencia en pacientes con EPOC: estudio de método mixto

Ana Paula Coelho Figueira Freire', Juliana Souza Uzeloto², Bruna Spolador de Alencar Silva ${ }^{3}$, Marcia Rodrigues Costa Franco ${ }^{4}$, Dionei Ramos 5 , Ercy Mara Cipulo Ramos 6

\begin{abstract}
I This study sought to quantify and qualitatively analyze the perception of physical therapists about facilitators and the challenges in the use of different types of tools for resistance training in chronic obstructive pulmonary disease (COPD) patients. This was a mixed-model study with qualitative analysis developed in a rehabilitation center. Six physical therapists who performed a randomized clinical trial were interviewed. The protocol consisted of the evaluation of three types of resistance training: elastic tubes, elastic bands, and training with conventional weight machines. After completion of the randomized trial, therapists were invited to participate in a focus group to collect qualitative data. Physical therapists also answered a quantitative questionnaire containing closed questions. The main outcome measures were the opinion of physical therapists about the advantages and disadvantages in clinical practice of each of the analyzed tools. The focus group analysis resulted in eight themes: Insecurities regarding load and handling tools, implementation of home-based treatment, improvements of tools, advantages and disadvantages of tools, incidence of injuries with elastic tools, patient's preferences, and particularities of the tools. Physical therapists pointed out different challenges and facilitators for resistance training. Characteristics of the tools such as costs, portability, handling
\end{abstract}

and practicality were cited as factors that influence clinical practice. In the quantitative analysis, no differences were observed when comparing the scores of each instrument. The three tools analyzed are applicable and feasible in the clinical practice of physical therapists; moreover, they present different characteristics and particularities that should be considered, such as cost, clinical applicability, portability and perception of the patient and therapists.

Keywords | Pulmonary Disease; Exercise Training; Pulmonary Rehabilitation; Physical Therapy; Qualitative Methods.

RESUMO I O objetivo do estudo foi quantificar e analisar qualitativamente a percepção de fisioterapeutas sobre facilitadores e barreiras no uso de diferentes ferramentas para treinamento resistido em pacientes com doença pulmonar obstrutiva crônica (DPOC). O método utilizado foi desenvolvido em um centro de reabilitação. Seis fisioterapeutas que participaram como terapeutas de um ensaio clínico randomizado foram entrevistados. O protocolo consistiu na avaliação de três ferramentas para treinamento resistido: tubos elásticos, bandas elásticas e treinamento convencional com equipamentos de musculação. Depois da finalização do ensaio clínico randomizado, os fisioterapeutas foram convidados a

\footnotetext{
Universidade Estadual Paulista (Unesp) - Presidente Prudente (SP), Brazil. E-mail: anapcff@hotmail.com. Orcid: 0000-0002-2805-5746 2Universidade Estadual Paulista (Unesp) - PresidentePrudente(SP), Brazil.E-mail:juliana_uzeloto@hotmail.com. Orcid:0000-0003-0158-3693 ${ }^{3}$ Universidade Estadual Paulista (Unesp) - Presidente Prudente (SP), Brazil. E-mail: brunaspolador@gmail.com. Orcid: 0000-0002-9085-9251 ${ }^{4}$ Universidade Estadual Paulista (Unesp) - Presidente Prudente (SP), Brazil. E-mail: marciafranco@gmail.com. Orcid: 0000-0001-6174-2524 5Universidade Estadual Paulista (Unesp) - Presidente Prudente (SP), Brazil. E-mail: dionei-ramos@bol.com.br. Orcid: 0000-0002-2956-7399 6Universidade Estadual Paulista (Unesp) - Presidente Prudente (SP), Brazil. E-mail: ercy@bol.com.br. Orcid: 0000-0002-3310-7336
} 
participar de um grupo focal para análise qualitativa e responder questionário fechado para análise quantitativa. Os profissionais opinaram sobre vantagens e desvantagens de cada uma das três ferramentas na prática clínica. A análise do grupo focal resultou em oito temas: insegurança em relação à carga e manuseio das ferramentas; implementação de tratamento domiciliar; melhorias para ferramentas; vantagens e desvantagens das ferramentas; incidência de lesões com ferramentas elásticas; preferência dos pacientes; e particularidades de cada ferramenta. Fisioterapeutas apontaram diferentes barreiras e facilitadores para o treinamento resistido. Características das ferramentas como custo, portabilidade, manuseio, praticidade e percepção do paciente e fisioterapeuta - foram citadas como fatores que influenciam a prática clínica. Na análise quantitativa, nenhuma diferença foi observada quando comparados os escores para cada instrumento. As três ferramentas são aplicáveis na prática clínica do fisioterapeuta. Adicionalmente, as características e particularidades de cada uma delas devem ser consideradas. Descritores | Doença Pulmonar; Treinamento Físico; Reabilitação Pulmonar; Fisioterapia; Método Qualitativo.

RESUMEN I El objetivo del estudio fue cuantificar y analizar cualitativamente la percepción de fisioterapeutas sobre facilitadores y barreras en el uso de diferentes herramientas de entrenamiento de resistencia en pacientes con enfermedad pulmonar obstructiva crónica (EPOC). El método utilizado fue desarrollado en un centro de rehabilitación. Seis profesionales que participaron como terapeutas en un ensayo clínico aleatorizado fueron entrevistados. El protocolo consistió en la evaluación de tres herramientas de entrenamiento de resistencia: tubos elásticos, bandas elásticas y entrenamiento convencional con equipo de entrenamiento con pesas. Después del ensayo clínico aleatorizado, se invitó a los fisioterapeutas a participar en un grupo focal para análisis cualitativo y a responder un cuestionario cerrado para análisis cuantitativo. Los profesionales opinaron sobre las ventajas y desventajas de cada una de las tres herramientas en la práctica clínica. El análisis del grupo resultó en ocho temas: falta de fiabilidad en lo referente a la carga y al manejo de las herramientas; puesta en práctica del tratamiento domiciliario; mejoras en las herramientas; ventajas y desventajas de las herramientas; incidencia de lesiones con las herramientas elásticas; preferencia de los pacientes; particularidades de cada herramienta. Los fisioterapeutas señalaron diferentes barreras y facilitadores para el entrenamiento de resistencia. Características de la herramienta - como costo, portabilidad, manejo, practicidad y percepción del paciente y del fisioterapeuta - fueron mencionadas como factores que influyen en la práctica clínica. En el análisis cuantitativo no se observaron diferencias de puntaje entre los instrumentos. Las tres herramientas son aplicables en la práctica clínica del fisioterapeuta. Además, se deben considerar las características y particularidades de cada una de ellas.

Palabras clave | Enfermedad Pulmonar; Entrenamiento Fisico; Rehabilitación Pulmonar; Fisioterapia; Método Cualitativo.

\section{INTRODUCTION}

Chronic Obstructive Pulmonary Disease (COPD) is a major cause of morbidity worldwide. Estimates state that by 2030 , COPD will be the third most frequent cause of death globally ${ }^{1}$. Current international guidelines emphasize the central role of pulmonary rehabilitation in the treatment of $\mathrm{COPD}^{2}$. Pulmonary rehabilitation aims to control COPD symptoms, reestablish and improve functional ability, enhance participation the activities of daily living, promote autonomy and improve the quality of life among this population ${ }^{3}$.

Exercise training has been considered an essential component of pulmonary rehabilitation programs ${ }^{3,4}$. Several training modalities have been used, including resistance training, since the muscular weakness found in these patients is associated with prognosis and functionality in these individuals ${ }^{2-4}$. Several tools can be used to improve muscle strength in these patients such as weight machines, dumbbells, ankle weights and elastic components (e.g., elastic tubes and elastic bands) ${ }^{5-7}$.

The selection of the tool that will be used in resistance training may depend on several aspects, such as the location where the training will happen, availability of resources, cost, portability, patient characteristics, and the training and perception of the physical therapist who will administer the resistance training ${ }^{8,9}$. Previous quantitative studies have reported that the outcomes of patients improve when the resistance training is conducted by trained physical therapists $^{10,11}$. Nevertheless, the perceptions of physical therapists after conducting such training have not been investigated. The investigation of such perspectives may be important given that, while resistance training is beneficial to COPD patients, if therapists are not confident or unwilling to administer it, such approach may not be one that can be routinely incorporated with ease in the clinical setting. Therefore, this study sought to quantify and qualitatively analyze the perception of physical therapists 
about facilitators and challenges in the use of different types of tools for resistance training in COPD patients.

\section{METHODOLOGY}

Six physical therapists who performed a randomized clinical trial at a rehabilitation center located in Presidente Prudente, Brazil were invited and agreed to participate in this study.

Individuals were previously informed on the research objectives and procedures and, upon acceptance, signed an informed consent form, in accordance with the Declaration of Helsinki of the World Medical Association.

The resistance training protocol of the randomized clinical trial consisted of the evaluation of three groups of COPD patients. The first group performed resistance training with elastic tubes (Lemgruber ${ }^{\circledR}$, Brazil), the second performed training with elastic bands (Therabanb ${ }^{\circledR}$, USA) and the third performed training with conventional weight machines (Ipiranga, Brazil).

The intervention occurred between September 2015 and June 2016 and lasted 12 weeks, with a frequency of three sessions per week. The same muscle groups (shoulder flexion, elbow flexion, shoulder abduction, knee extension, and knee flexion) were trained in all three types of training, using the same muscle strengthening protocol. Training with bands and elastic tubes occurred in chairs especially designed for the exercises (containing hooks that allowed the fixing of elastic bands and tubes) ${ }^{12}$.

Therapists underwent training prior to the beginning of the training protocol to familiarize themselves and standardize sessions using all the tools evaluated in the study. At the beginning of the training, patients were randomly distributed among therapists so all therapists could perform the three tools analyzed.

To perform the three types of training, the patients worked with a protocol of maximum number of repetitions in each set. The protocol was based on a previous study of our research group ${ }^{7,12}$.

After completion of the randomized clinical trial, the therapists participating in the trial were invited to participate in a focus group to collect qualitative data. The focus groups were led by the main researcher of this study and conducted using an interview guide containing openended questions (Table 1). The moderator was a female $\mathrm{Ph} . \mathrm{D}$ student, with previous training and experience in qualitative research; a second researcher also participated in the interview to take notes.
Table 1. Interview guide used in the focus group

Qualitative questions

1. Have you ever found difficulties to use elastic tubes and/or elastic bands in clinical practice? If yes, what difficulties?

2. What are the main disadvantages of elastic tubes and/or elastic bands?

3. Is there any difficulty to use weight machines? If yes, what difficulties?

4. Is there any advantage to using elastic tubes and/or elastic bands? If yes, which ones?

5. Is there any advantage to using weight machines? If yes, which ones?

6. During training, what was your perception of satisfaction of the patients about the tools used?

7. Considering only the practicality of each tool (not considering costs or benefits), which tool would you use in clinical practice? Why?

8. Considering the cost-benefit of each tool, which one would you use in clinical practice?

The focus group was conducted in the rehabilitation center where the therapists worked. The interview was recorded in audio (OLYMPUS / VN-8100PC, Tokyo, Japan) and later transcribed verbatim. Table 1 shows the interview guide used in the focus group.

The focus group lasted approximately 50 minutes. Data were collected until no new information was acquired (data saturation point $)^{13,14}$.

After completion of the focus group, the physical therapists answered a quantitative questionnaire containing closed questions. The questions were on the opinion of therapists about the advantages and disadvantages of each of the analyzed tools - elastic tubes, elastic bands and weight training equipment. The questionnaire is presented in Table 2. Finally, therapists were asked to assign a grade from 0 to 10, with 0 being the worst grade, considering the general aspects of each tool.

Table 2. Quantitative questions

Questions - Quantitative questionnaire
Advantages of each tool
$\begin{aligned} & \text { 1. Satisfaction of the patient } \\ & \text { 2. Cost-benefit } \\ & \text { 3. Clinical practicality } \\ & \text { 4. Portability } \\ & \text { 5. Gains for the patient } \\ & \text { Disadvantages of each tool } \\ & \text { 1. Injuries on the patient } \\ & \text { 2. Difficulties using the tool } \\ & \text { 3. Dissatisfaction of the patient } \\ & \text { 4. Low gain for the patient } \\ & \text { 5. Cost-benefit }\end{aligned}$




\section{Data analysis}

Qualitative data were analyzed using content analysis, which is a systematic way of describing phenomena and allows researchers to improve their understanding of data by refining words in fewer categories related to the content ${ }^{15}$. By analyzing the content, words can be distilled in less related categories to provide knowledge, new insights, representation of facts and a practical guide for action $^{15}$.

The transcripts of the focus groups were analyzed by three independent researchers to identify and classify the categories related to the research question. The analysis was developed by categorizing, organizing and compacting data. After initial analysis, all researchers discussed the differences in the results until a consensus was reached (triangulation). The final results were then sent to participants to check whether the findings really reflected their perspectives and points of view. Analyses were performed and stored in the HyperRESEARCH 3.7.3 program.

To analyze quantitative data, we used ShapiroWilk's test for data normality analysis and then applied KruskalWallis' test with Dunn's post test. Statistical software GraphPad Prism was used, and the significance level was set at $5 \%$.

\section{RESULTS}

The six therapists finalized all the proposed evaluation processes. All physical therapists had an undergraduate degree in Physical Therapy and applied the exercise training with the three tools.

The mean age of participants was $23.83 \pm 2.04$ years, and on average, the participants were $1.72 \pm 1.73$ years after end of graduation. Moreover, they were working in the pulmonary rehabilitation area for $1.68 \pm 1.74$ years.

\section{Qualitative analysis}

The interview resulted in eight items, as described below.

\section{Insecurities regarding the identification of the load} imposed on the patient

Therapists found difficulties in using the elastic tools, especially to determine the accuracy of the initial load imposed on the patient and the load used in the progression of the training. Since elastic tools do not present a pre-determined load and their load is variable during the execution of the movements, the quantification of the load depends totally on the therapist's perception. This factor was considered a possible challenge to the use of elastic tools.

Finding the initial load imposed on the patients to start the training. I believe that after you started too, it's easier for you to do the increment, but starting is more complicated. (Therapist 1)

Incrementing is easier but finding this initial load is kind of difficult. (Therapist 1 )

Moreover, the difficulty to identify the load exerted by the elastic tools also generated concerns related to the tendency to underestimate or overestimate the load that would be ideal for each patient.

It is difficult to find out what is the load for the patient, to not to underestimate or overestimate it. I think it is easy to overestimate using tube and Theraband. (Therapist 2)

We do not know how much resistance each tube offers, according to the stretch of it, it gets complicated... If we knew... Oh, this tube has a certain percentage of stretch, offers this resistance, would be much easier to adjust. Because you would start from a principle that you already know how much you will offer. We still do not know, so we go as we see. (Therapist 3)

With the tube you do not regulateladjust, that's it and done. Not there (weight machines), you can gradually increase, I think that is the main advantage. (Therapist 4)

When comparing the elastic tools, they reported greater easiness in identifying the load on the elastic bands, since the band (Theraband) provides the load (in kilograms) according to color and percentage of deformation in relation to the initial movement. Regarding the elastic tubes, it is known that larger diameters offer greater resistance to the patient.

In fact the biggest advantage in using Theraband over the elastic tube is that you know the grade of the resistance offered according to the stretch. It's the only difference, the rest is the same. (Therapist 4 )

In fact, I think the biggest difficulty of the tube is when you start working with it, to understand the load graduation 
of it, a matter of diameter, but after you get it, I think it is not difficult at all. (Therapist 4)

\section{Difficulties regarding handling the resistance tool}

Therapists reported greater difficulties regarding the handling of elastic tools when compared to conventional weight machines. Reports on the difficulty of tube and band replacement were frequent.

Therapists reported that more effort is required in the dynamic of the training with elastic tools because frequent changes of elastic resistances on upper limb and lower limb exercises are necessary, since larger diameter tubes or bands of different colors are required for different movements.

I think the change of tubes also, for different movements, is a bit complicated, both in the tube and in the Theraband. (Therapist 1)

We have to change it all the time. (Therapist 5)

This changing thing is a lot of effort... For the therapist is more tiring, more exhausting. (Therapist 1 )

[Regarding weight machines] No need to change here, putting and removing, no, you set the load and it is done, finish the set and only change when you change the point of movement. You do not have to spend all the time changing limbs, putting loads, so the practicality of working is a lot better. (Therapist 4)

One of the therapists also stressed that handling with elastic bands (Theraband) can still be more laborious than tubes.

Theraband is still more laborious, because it tangles. So, to hook it, I think it is harder, tougher, you have to keep opening it. I prefer the tube, I think it is much easier to work with. (Therapist 4)

Additionally, a challenge found in the elastic tools was the material that, on certain occasions, provided difficulties during the resistance training sessions.

One of the disadvantages of the elastic tools is that it periodically bursts. If the patient is using it, it bursts in the middle of the movement. (Therapist 4)
Due to these difficulties observed by the therapists regarding the handling of the elastic tools, each session lasted for a longer period of time when using these tools when compared to the training performed using conventional weight machines.

Time is much faster (in weight machine), what we do in one hour using the tube, we do in half hour, 35 minutes using weight machines. (Therapist 3 )

And in two patients. (Therapist 1)

\section{Implementation of home-based treatment}

The chair used during the training was designed by the researchers specifically for training with elastic tools, and it can be used in the rehabilitation center and at the patients' home after supervised training. However, some obstacles were identified, such as the difficulty that the patient would probably face to change tubes or bands without assistance, and the different loads of the elastic tools.

Seeking the independence of the patient during training, I think is a bit difficult. Because using weight machine, for example, if the patient had machines like that at home, it would make easier to set the loads. I think the chair is different, the patient needs help from someone at home (...) to change them, otherwise the patient has to get off the chair to put the tube or the band on the hook. So, I think that's a harder thing to make the patient independent. (Therapist 3)

Another indication regarding the use of the elastic tube at home was the possible difficulty in identifying the resistances, and the therapists suggested coloring them.

I think Theraband is easier for the patient. It is much easier for the patient to know what color he has to put on than to identify the thickness of the tube. (Therapist 6)

Regarding the difficulty in portability of the chair, it was suggested to implant fixed bars in the patients' homes to facilitate the use of the elastic tools, as well as the fixation of handles for better handling of the elastic tools.

It does not even need to be a chair. Any fixed bar or hook that the patient has at home already helps training. (Therapist 1)

Would have to put a handle. (Therapist 5) 
They also emphasized that despite the difficulties that may occur in the patient's house, elastic tools are the most viable options to continue unsupervised resistance training, which was considered an advantage when compared to weight machines.

Even though it is difficult for the patient to do the training with the elastic resistance, the patient can continue the training, taking the equipment home, unlike the weight machines. (Therapist 1)

In addition to the possibility of using elastic tools at home, it was also pointed out that these tools have the advantage of being used in other environments that do not have conventional weight machines.

Because you can work with this type of patient in any environment, in your clinic you do not have to have a weight machine. It is much easier to get the tube and the Theraband and you can take it to any place, the health care unit, the hospital, the patient's house. (Therapist 2)

\section{Suggested improvements to the tools}

Therapists reported that the use of elastic tube for muscle strengthening in COPD patients is a new method, and they observed some limitations that could be fixed in the future.

It's a new thing, too, there's a lot to study, there's a lot of adaptations to make, a lot of questions to improve for the patient and the therapist. (Therapist 4)

They also made suggestions on how to make elastic tubes colored, since only tubes of a single color (yellow) were used. The purpose is to make the tubes more attractive to the patients and easier to identify the resistance of different diameters.

If it had a color to characterize each tube, for example, the same as on Theraband, blue is 01, green is 02, it would be easier. (Therapist 5)

I think putting colors on the tubes will make identification easier for those who are starting to use it. (Therapist 6)

Improving the portability of the chair used to fix the elastic tools, as well as adaptations for the tools were also proposed, when considering home training as an option.
Because it is a chair that you can't take home. I think about its size, we would have to do something more portable. (Therapist 5)

I think it has to be a folding chair, I know that is not easy, but a chair that folds, that I can keep it somewhere, and then open it and have some hooks. I think that's the ideal. (Therapist 5)

Maybe if the hooks were a little bigger they would help too. (Therapist 3)

\section{Advantages and disadvantages of different too/s}

The therapists mentioned different points of view when questioned about the preference for tools used in clinical practice. One of the therapists' notes revealed costs of the tools and the similarity in the perception of physical gains.

Because when you compare with the elastic band, it is much cheaper. With what you spend to assemble a kit (of tubes), you buy a single Theraband. So, in my opinion, there is no difference in gains comparing both, but costbenefit, certainly the tube. Because practicality is the same. (Therapist 4)

I think the main advantage is the cost-benefit... The easiness of having the tool for training, it is much easier to have the elastic tools, either the tube or Theraband, more the tube because of the value, more than the weight machine. And when you see the gains, the patient can have the same gains as using the weight machine, elastic tools are more interesting. (Therapist 1)

In another point, the therapists mentioned the greater easiness of weight machines in clinical practice.

Practicality to work (...). You put the load and it is ready, finish the set and only change load when changing the point of movement. You do not need to change limbs all the time, add weight, so the practicality when working is far greater. (Therapist 4)

You do not have to change when using weight machines, you just set the weight on the side and that's it, the patient starts to work. I think so, for the therapist it is more tiring, more exhausting. Training using weight machines is much faster than tube or Theraband. (Therapist 1) 
Another facilitator for the use of weight machines was the time spent per patient and the possibility to attend more patients at a time.

With weight machines you can attend four. With the tube it is impossible. (Therapist 5)

With tube two per hour, if you need to train three, it will be one hour and a half. (Therapist 1)

Time is much faster, what we did in an hour using the tube, we do in 30-35 minutes using weight machines. (Therapist 3)

\section{Concerning about the incidence of injuries with elastic tools}

Therapists were concerned about the occurrence of injuries during training.

But what happened regarding injury, the patient could not use that load with the tube (...). Because we do not know how much this tube offers, whether that was the reason or something else or it was a coincidence of the patient using the tube. But the patients that got injured, it was not an injury; at the end of the training it was necessary to decrease the load of the tube and Theraband. I did not see this happening when using weight machines. (Therapist 2)

\section{Patient's preferences regarding different too/s}

Therapists were asked about their perception of patients' preferences in the three training sessions (i.e., elastic tubes, elastic bands and weight machine equipment). Most therapists observed greater satisfaction with training using weight machines.

The thing about being in a machine, thinking that it is more expensive, it looks better, they wanted to use weight machines. (Therapist 6)

In all three tools we had people who did not like (...). But in general, the one with most acceptance was the weight machine. The tube, in my opinion, was worse than Theraband. I think because it was colored (theraband), it draws more attention. (Therapist 4)

I think there's also the acceptance of the patient (...). In private clinics sometimes they'd better accept a clinic that has weight machines than one with tubes. (Therapist 6)
Another observation was about training time.

It's a matter of time, everyone using elastic tools complained that the patients using weight machines left a long time before. They [elastic resistance] took about 20-25 minutes longer. (Therapist 3)

\section{Particularities of the tools}

The physiological mechanisms of elastic resistance were highlighted, especially about the concentric phase of the exercise.

So, for me the elastic resistance, with tube and Theraband, they control the eccentric phase a lot better, it works a lot better than using the weight machine, it is my perception. (Therapist 4)

Some aspects about the execution of the movements using different tools were pointed out by the therapists, in this topic there were divergences in the responses obtained.

I think you have to be a little more attentive when the patient is using the weight machine because of the compensation, I think in the chair (used in the training with elastic tools) they compensate less. (Therapist 2)

When they were doing it on the chair (elastic components), they did not complete the movement, they did not make the complete movement arc and I think when they were using weight machines, they were doing it better. (Therapist 3)

I think that with the tube you have to be more attentive than with the weight machine considering the arc of movement. (Therapist 1)

\section{Quantitative analysis}

In the quantitative analysis, we found that $50 \%$ of the therapists considered the gains observed in the patients to be the main advantage of the elastic tube. For elastic bands, $33.33 \%$ of therapists believe that the main advantage was the gains observed in patients, and $33.33 \%$ said that the main advantage is its clinical practicality. For weight machines, the main advantage reported was also the gains observed in the patients (Figure 1). 

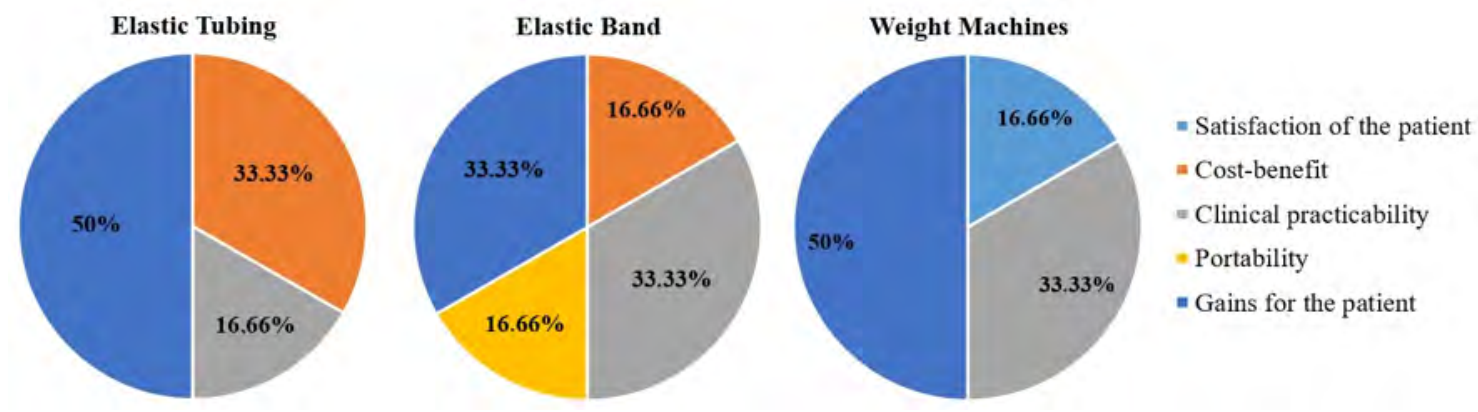

Figure 1. Quantitative analysis of advantages in each tool used

Regarding the disadvantages of each tool, the therapists pointed out difficulties of applicability for elastic tools (tubes and elastic bands). For weight machines, the main disadvantage reported was the cost-benefit. This information can be seen in Figure 2.

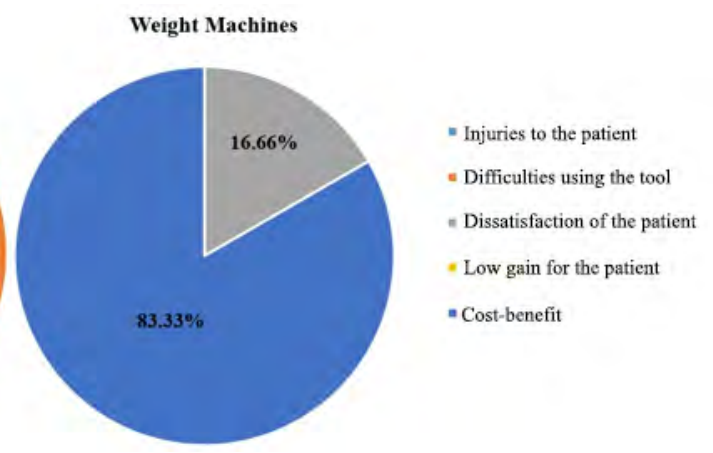

Figure 2. Quantitative analysis of disadvantages in each tool

Finally, in the last part of the questionnaire, the therapists were asked to assign a score from 0 to 10 (considering 10 as the best score) for each tool, considering their experience and general aspects of each instrument. Weight machines received the highest score $(8.50 \pm 1.04)$, followed by elastic bands $(7.83 \pm 0.75)$ and elastic tubes $(7.66 \pm 0.81)$, but there was no statistical difference between the three tools $(\mathrm{p}=0.2987)$. This data can be seen in Figure 3.

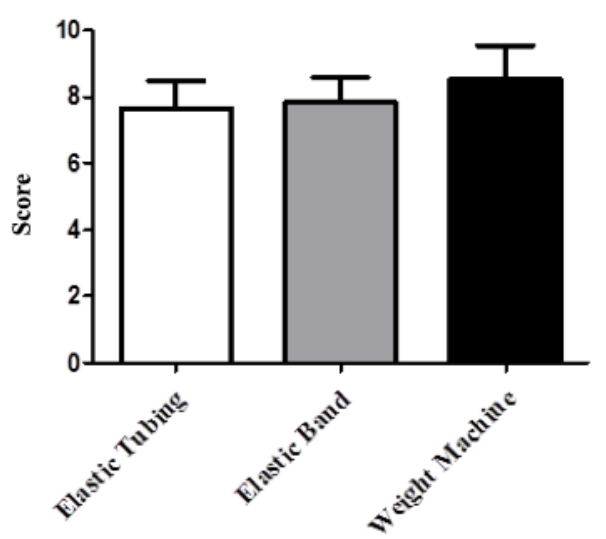

Figure 3. Scores attributed to each tool by physiotherapists

\section{DISCUSSION}

In this study we observed that physical therapists pointed out different challenges and facilitators in the use of three different tools for resistance training in COPD patients. Characteristics of the tools such as costs, portability, handling and practicality were cited as factors that influence clinical practice. In the quantitative analysis, no differences were observed when comparing the scores of each instrument.

The elastic tools have gained space in rehabilitation protocols because they are portable, have low cost and easy maintenance ${ }^{16,17}$. These instruments allow a larger range of motion with concentric and eccentric muscle contractions ${ }^{17}$. On the other hand, weight machines are not as financially accessible, have higher maintenance costs, and require more physical space, which may limit their use in the patients' house ${ }^{18}$. These characteristics were pointed out by the therapists as important aspects that influence clinical practice. The possibility of home use of elastic tools as an alternative was mentioned as a facilitator, in addition to cost-reduction in clinical practice and the perception that these instruments provide similar gains when compared to weight machines. 
Studies have demonstrated similar results when comparing weight machines and elastic tools. Ramos et al. ${ }^{7}$ observed similar gains in muscle strength and functional capacity when comparing these tools in COPD patients. In sedentary middle-aged women, the same changes in body composition were also observed when comparing these two types of resistance training ${ }^{16}$. However, qualitative studies demonstrate that the opinion of patients and therapists concerning these tools are still scarce in the literature.

O'Shea et al. ${ }^{17}$ offered resistance training with elastic bands, using a protocol similar to the one in this study, also in patients with COPD. After the intervention, the patients were invited to participate in a focus group. Patients' perceptions, in certain aspects, corroborate with the findings of our study. The patients of O'Shea's study ${ }^{17}$ also reported the rupture of elastic bands during exercise as a negative aspect, in addition to considering the exercises boring. These aspects were also mentioned by the therapists in our study as possible challenges for the use of elastic tools.

Another situation highlighted by O'Sheaet al. ${ }^{17}$ was the perception of load exerted by elastic instruments. Some patients showed higher fatigue and reported high intensity as perception of the exercise performed. Similarly, in this study, therapists expressed some concerns about the imprecision of the load using these instruments. We must note that the quantification of the load of elastic tools is not clear in the literature. This is due to the different elongation coefficients of elastic components and their modification during the exercise ${ }^{18}$. When an elastic component is used, the tension promoted will linearly increase from the beginning of the contraction up to the end of the range of motion, providing resistance not only in the vertical plane but also across the range of motion ${ }^{18,19}$.

The particularities of elastic tools inhibit the precise determination of load. However, these very aspects are also responsible for requiring greater muscle activation and use of faster motor units ${ }^{19}$. This finding suggests an urgent need to determine specific equations for each type of elastic band to better explain these aspects.

In the quantitative analysis, a greater percentage of the physical therapists mentioned the gains of the patients as the main advantage for the three tools. For disadvantages, the therapists cited the difficulty of applicability as the main weakness of elastic tools, and cost-benefit for weight machines. Despite the characteristics observed, no significant differences were observed for the three tools when considering the scores attributed by the physical therapists. Based on these results, we note that solutions for the implementation of pulmonary rehabilitation are necessary, emphasizing low-cost alternatives that can increase the offer of this type of program. Alison et al. demonstrated that exercise training using minimal equipment is effective in improving outcomes of functional exercise capacity and health-related quality of life in COPD patients ${ }^{9}$. Our study presents a possible and viable tool for this purpose.

The present study has contributed importantly to a better understanding of facilitators and barriers of resistance training in patients with COPD. This is the first study demonstrating the physiotherapist view about different resistance training tools. These findings may help other professionals to make decisions that influence their clinical practice and may make the treatment of these patients more effective.

Thus, we conclude that, qualitatively, the gains achieved by the patients was the main advantage for the three tools. For disadvantages, therapists pointed the difficulty of applicability as the main weakness of elastic tools, and the cost benefit for weight machines. Despite these particularities, no differences between the tools were reported in general aspects, demonstrating that that the three tools analyzed are applicable and feasible in the clinical practice of physical therapists.

\section{REFERENCES}

1. World Health Oranization. Burden of COPD. Geneva: World Health Organization; 2015. [cited 2017 Mar 3]. Available from: http://www.who.int/respiratory/copd/burden/en/2015

2. Maltais F, Decramer M, Casaburi R, Barreiro E, Burelle Y, Debigaré R, et al. An official American Thoracic Society/ European Respiratory Society Statement: update on limb muscle dysfunction in chronic obstructive pulmonary disease. Am J Respir Crit Care Med. 2014;189(9):e15-e62. doi: 10.1164/ rccm.201402-0373ST

3. Spruit MA, Burtin C, De Boever P, Langer D, Vogiatzis I, Wouters EFM, et al. COPD and exercise: does it make a difference? Breathe. 2016;12(2):e38-e49. doi: 10.1183/20734735.003916

4. Bettoncelli G, Blasi F, Brusasco V, Centanni S, Corrado A, De Benedetto F, et al. The clinical and integrated management of COPD: an official document of Aimar (Interdisciplinary Association for Research in Lung Disease), Aipo (Italian Association of Hospital Pulmonologists), Simer (Italian Society of Respiratory Medicine), Simg (Italian Society of General Medicine). Multidiscip Respir Med. 2014;9(1):25. doi: 10.1186/2049-6958-9-25 
5. Ricci-Vitor AL, Bonfim R, Fosco LC, Bertolini GN, Ramos EM, Ramos D, et al. Influence of the resistance training on heart rate variability, functional capacity and muscle strength in the chronic obstructive pulmonary disease. Eur J Phys Rehabil Med. 2013[cited 2019 July 5];49(6):793-801. Available from: https:// www.minervamedica.it/en/journals/europa-medicophysica/ article.php?cod=R33Y2013N06A0793

6. Nyberg A, Lindstrom B, Rickenlund A, Wadell K. Low-load/ high-repetition elastic band resistance training in patients with COPD: a randomized, controlled, multicenter trial. Clin Respir J. 2015;9(3):278-88. doi:10.1111/crj.12141

7. Ramos EM, de Toledo-Arruda AC, Fosco LC, Bonfim R, Bertolini GN, Guarnier FA, et al. The effects of elastic tubing-based resistance training compared with conventional resistance training in patients with moderate chronic obstructive pulmonary disease: a randomized clinical trial. Clin Rehabil. 2014;28(11):1096-106. doi: 10.1177/0269215514527842

8. Andrianopoulos V, Klijn P, Franssen FM, Spruit MA. Exercise training in pulmonary rehabilitation. Clin Chest Med. 2014;35(2):313-22. doi: 10.1016/j.ccm.2014.02.013

9. Alison JA, McKeough ZJ. Pulmonary rehabilitation for COPD: are programs with minimal exercise equipment effective? J Thorac Dis. 2014;6(11):1606-14. doi: 10.3978/j.issn.2072-1439.2014.07.45

10. Puente-Maestu L, Sanz ML, Sanz P, Cubillo JM, Mayol J, Casaburi R. Comparison of effects of supervised versus self-monitored training programmes in patients with chronic obstructive pulmonary disease. Eur Respir J. 2000[cited 2019 July 5];15(3):517-25. Available from: https://erj.ersjournals.com/content/15/3/517.long

11. Ashworth NL, Chad KE, Harrison EL, Reeder BA, Marshall SC. Home versus center based physical activity programs in older adults. Cochrane Database Syst Rev. 2005(1):Cd004017. doi: 10.1002/14651858.CD004017.pub2

12. Silva BSdA, Gobbo LA, Freire APCF, Trevisan IB, Silva IG, Ramos EMC. Effects of a resistance training with elastic tubing in strenght, quality of life and dyspnea in patients with chronic obstructive pulmonary disease. J Phys Educ. 2016;27. doi: 10.4025/jphyseduc.v27i1.2722

13. Mellion LR, Tovin MM. Grounded theory: a qualitative research methodology for physical therapy. Physiother Theory Pract. 2002;18(3):109-20. doi: 10.1080/09593980290058490

14. Cutcliffe JR. Methodological issues in grounded theory. J Adv Nurs. 2000;31(6):1476-84. doi: 10.1046/j.1365-2648.2000.01430.x

15. Elo S, Kyngas $H$. The qualitative content analysis process. J Adv Nurs. 2008;62(1):107-15. doi: 10.1111/j.1365-2648.2007.04569.x

16. Colado JC, Triplett NT. Effects of a short-term resistance program using elastic bands versus weight machines for sedentary middle-aged women. J Strength Cond Res. 2008;22(5):1441-8. doi: 10.1519/JSC.0b013e31817ae67a

17. O'Shea SD, Taylor NF, Paratz JD. Qualitative outcomes of progressive resistance exercise for people with COPD. Chron Respir Dis. 2007;4(3):135-42. doi: 10.1177/1479972307075313

18. Saeterbakken AH, Andersen V, Kolnes MK, Fimland MS. Effects of replacing free weights with elastic band resistance in squats on trunk muscle activation. J Strength Cond Res. 2014;28(11):3056-62. doi: 10.1519/JSC.0000000000000516

19. Melchiorri G, Rainoldi A. Muscle fatigue induced by two different resistances: elastic tubing versus weight machines. J Electromyogr Kinesiol. 2011;21(6):954-9. doi: 10.1016/ j.jelekin.2011.07.015 